\title{
Genotypic and phenotypic correlates with proliferative kidney disease-induced mortality in Atlantic salmon
}

\author{
Eef Cauwelier ${ }^{1, *}$, John Gilbey ${ }^{1}$, Catherine S. Jones ${ }^{2}$, Leslie R. Noble ${ }^{2}$, Eric Verspoor $^{1}$ \\ ${ }^{1}$ Marine Scotland Freshwater Laboratory, Faskally, Pitlochry PH16 5LB, UK \\ ${ }^{2}$ Zoology Department, School of Biological Sciences, University of Aberdeen, Tillydrone Avenue, Aberdeen AB24 2TZ, UK
}

\begin{abstract}
Heritable variation in resistance to pathogens has been reported in many fish species, but little is known about its genetic architecture. To extend understanding, an investigation was made of the association of resistance to proliferative kidney disease (PKD) in 4 second filial generation $\left(\mathrm{F}_{2}\right)$ families of Atlantic salmon with molecular markers from different genetic linkage groups in the species' genome, following a natural disease outbreak. PKD causes serious mortality in cultured salmonids. In addition to mortality, associations with growth-related traits were also examined, as immune responses are energetically costly and have been observed to reduce growth. Associations were investigated for 34 microsatellite markers and 5 restriction fragment length polymorphism (RFLP) loci from 3 regions of the growth hormone 1 gene (GH1). The phenotypic and genotypic character of survivors was compared with unexposed fish derived from the same families. Mortality was not size-selective, but growth in the survivors was reduced, and fish had a lower condition factor than unexposed fish, suggesting an energetic cost to resistance. Five markers showed significant allele frequency differences between survivors and unexposed fish, albeit in single families. Prior to correction for multiple tests, 2 of these markers were also linked to variation in growth-related traits among survivors, along with a further 7 markers. Though sample sizes constrained the power of the analysis, the study points to regions of the salmon genome that may contain quantitative trait loci related to PKD resistance, on which further work on the genetic architecture of PKD resistance in this species could focus.
\end{abstract}

KEY WORDS: Proliferative kidney disease $\cdot$ PKD $\cdot$ Atlantic salmon $\cdot$ Resistance $\cdot$ Growth $\cdot$ Markertrait associations $\cdot$ Quantitative trait locus $\cdot$ QTL

Resale or republication not permitted without written consent of the publisher

\section{INTRODUCTION}

Heritable variation between and within populations in their resistance to pathogens (including parasites) has been reported in many fish species (Price 1985, Gjedrem 2000, Coltman et al. 2001), including Atlantic salmon Salmo salar (Gjedrem et al. 1991, Mustafa \& MacKinnon 1999). However, our understanding of the genetic architecture of pathogen resistance, such as which genes and gene interactions underpin variation in these quantitative traits, remains limited. In Atlantic salmon, this is in partly due to the long generation times required to create informative second-generation families for gene mapping studies. Yet knowledge of the genetic architecture of resistance is essential to understand the genetic basis of adaptive differentiation among wild populations (e.g. for Gyrodactylus salaries) (Bakke et al. 2004), as well as to gain knowledge of the relevant quantitative trait loci (QTL) (Lande \& Thompson 1990) to design more effective selective breeding programmes.

Insight into the basic genetic architecture of pathogen resistance/susceptibility can be gained through family-based experiments by examining associations between genotypic and phenotypic variation in resistance-related traits such as survival. Establishment of associations of molecular markers from different genome regions with a resistance-related phenotypic 
trait would help to identify regions of the genome containing potential QTL influencing this trait. This approach has been used successfully in a number of studies of salmonid fishes, in which differential mortality to disease was the trait examined (Moen et al. 2004a, Barroso et al. 2008, Houston et al. 2008). However, disease may or may not lead to increased direct mortality in a host population. Where pathogen virulence is low (Alexander 1981, Ewald 1983), overall fitness may be reduced indirectly through influences on other heritable traits, such as growth and body condition (Sheldon \& Verhulst 1996, Lochmiller \& Deerenberg 2000). Mounting an immune response to a disease is costly, as energy and resources are directed towards regulation of the immune system and become unavailable for other important somatic processes. Consistent with this view, reduced growth following infection has been observed in a number of species (Lochmiller \& Deerenberg 2000), including Atlantic salmon (Ellis et al. 1985). Thus, understanding of the genetic architecture of resistance also needs to consider the importance of heritable variation at genes that underpin variation in growth and growth-related fitness (Robison et al. 2001, Gilbey et al. 2005), which may be affected by the resistance response, e.g. the growth hormone 1 gene (GH1) (Björnsson 1997, Kuhnlein et al. 1997).

Infection with the myxozoan endoparasite Tetracapsuloides bryosalmonae, which causes proliferative kidney disease (PKD), occurs seasonally in many salmonid species and generally results in high levels of mortality (Hedrick et al. 1993). However, mortality rates are highly variable and often mediated through secondary infections. Furthermore, surviving fish appear to develop immunity against a second T. bryosalmonae infection (Hedrick et al. 1993), suggesting the involvement of an acquired immune response. Interspecific comparisons show some salmonid host species to be more resistant than others (Seagrave et al. 1981, Brown et al. 1991, Feist \& Bucke 1993), and the narrow sense heritability of resistance, following a natural outbreak, was estimated to be $h^{2}=0.19 \pm 0.08$, based on differences between 2 strains of rainbow trout Oncorhynchus mykiss (Butterfield 2008). Beyond this, genetical aspects of the disease remain poorly understood, including the extent of intraspecific genetic variation in resistance and the genetic architecture of the heritable response to the disease (Holland et al. 2003).

Here we report the results of a study of associations between the phenotypic and genotypic character of PKD resistance by analysing second filial generation $\left(F_{2}\right)$ families of Atlantic salmon following a serendipitous natural outbreak of the disease. Survivors were analysed with regard to growth-related, phenotypic traits (length, weight, and condition factor) and variation at 34 microsatellite markers and 5 loci in GH1.
Those data were compared with unexposed fish derived from the same families, as no analysis of mortalities was possible. A basic, single marker-single linkage group approach was used (Gilbey et al. 2006), whereby microsatellite markers were chosen to cover each linkage group of the linkage map of Gilbey et al. (2004), along with further markers from the linkage groups identified in SALMAP (www.asalbase.org/ sal-bin/index) and Moen et al. (2008). Furthermore, a growth hormone gene marker, not mapped to any identified linkage group, was screened to assess association with this region of the genome. The main objective of the study was to identify genome regions likely to contain genes important to resistance on which to focus more detailed fine-scale QTL mapping studies.

\section{MATERIALS AND METHODS}

Atlantic salmon families. The 4 experimental families included in the study consisted of $\mathrm{F}_{2}$ crosses between salmon originating from the Bristol Cove River $\left(46^{\circ} 63^{\prime} \mathrm{N}, 53^{\circ} 19^{\prime} \mathrm{W}\right)$, Canada, and from the river Don $\left(57^{\circ} 11^{\prime} \mathrm{N}, 3^{\circ} 6^{\prime} \mathrm{W}\right)$, Scotland. Mature adults from each source were crossed to produce first filial generation $\left(F_{1}\right)$ families. At age $2+, 4$ mature $F_{1}$ males were crossed to 4 mature $F_{1}$ females in a single mating crossing scheme. A total of 450 fish from each family $(\mathrm{n}=$ 1800) were reared in separate tanks at the MSS Freshwater Laboratory Rearing Unit at Almondbank, Scotland, until a proportion of fish were transported to the MSS Marine Laboratory Fish Cultivation Unit at Aultbea, Scotland, at 2 years of age. Prior to transport, a small piece of tissue was taken from different fins of fish from 3 of the families to allow external identification of the family of origin of each individual. Thereafter, the study fish were retained in 2 mixed family groups consisting of 300 and 150 fish from each family at Aultbea and Almondbank, respectively. Both groups were kept at equal densities and fed ad lib. The analysis of fish length and weight post-transport showed that the family groups, in both cases, consisted mainly of parr, but included some smolts.

Disease outbreak. Two weeks after the large mixed family group ( $\mathrm{n}=1200$ ) had been transported to Aultbea, it incurred significant mortality (90\%), and fish were treated with the antibiotic oxytetracycline for $10 \mathrm{~d}$, based on an assumption that the mortality factor was furunculosis (caused by the bacteria Aeromonas salmonicida. However, oxytetracycline proved ineffective. Ten survivors were analysed by the Fish Health Inspectorate at the MSS Marine Laboratory, Scotland, and histological analysis revealed that Tetracapsuloides bryosalmonae was the causative agent. Further analyses were carried out, on a variety of tissues, to 
assess potential infection with other viruses (infectious salmon anemia virus, viral haemorrhagic septicaemia virus, infectious haematopoietic necrosis virus, and infectuous pancreatic necrosis virus), bacteria ( $A$. salmonicida and Renibacterium salmoninarum) and/or parasites (Gyrodactylus salaris), but those analyses did not reveal any signs of secondary infections by those pathogens. These are the most frequent disease vectors associated with mortality in Atlantic salmon culture in Scotland (Fish Health Inspectorate pers. comm.). The PKD pathogen is not treatable by antibiotics, and malachite green and fumagillin are the only 2 chemotherapeutants capable of controlling this disease (le Gouvello et al. 1999). Based on this analysis, it is reasonable to conclude that the surviving fish $(10 \%$, $\mathrm{n}=120$ ) were those that were resistant to PKD, as opposed to another pathogen.

A total of $27 \mathrm{~d}$ after the start of the infection, when there had been no mortality for $13 \mathrm{~d}$, the standard length (mm), weight $(\mathrm{g})$, and family of each surviving fish were recorded and a fin clip taken for DNA analysis. Condition factor (CF) was calculated following the method of Wootton (1990). The unforeseen nature of the infection meant that phenotypic data were not available for fish prior to the infection or from the fish that died of PKD, nor was there genotypic data for fish that had died. To address this problem, data of the PKD survivors were compared to phenotype $(n=201)$ and genotype $(n=305)$ information obtained from a subsample of fish from the small mixed family group that had been retained at Almondbank and had, consequently, not been exposed to the disease. The phenotypic data on those fish had been collected $5 \mathrm{~d}$ earlier, on Day 22 after the start of the infection of the Aultbea group.

Molecular markers. A total of 34 variable microsatellite loci were screened. These were chosen to mark the linkage groups identified in the map of Gilbey et al. (2004), along with markers from the SALMAP, Moen et al. (2008), and a number of unlinked markers (Table 1). To screen for variation at these loci, total genomic DNA was extracted from fin clips ( $\mathrm{n}=425$ ) after Knox et al. (2002). PCR was performed in a $12.5 \mu$ reaction volume containing 5 to 100 ng DNA, 75 mM Tris- $\mathrm{HCl}$ (pH 8.8), $20 \mathrm{mM}$ $\left(\mathrm{NH}_{4}\right)_{2} \mathrm{SO}_{4}, 1.5 \mathrm{mM} \mathrm{MgCl} 2,200 \mu \mathrm{M}$ of each dNTP, $0.5 \mu \mathrm{M}$ of each primer, and 0.25 units of ABgene Taq DNA polymerase (ABgene). PCR cycling conditions consisted of a touchdown sequence detailed in Gilbey et al. (2004). Electrophoresis was carried out using a MegaBace 500 capillary sequencer (GE Healthcare).

In addition to these linkage group markers, the association of resistance with variation in GH1 region of the Atlantic salmon (Ryynänen \& Primmer 2004a) was assessed. Sequences of a published 4712 bp frag- ment of the GH1 (GenBank Accession \#AY614002AY614008) were aligned to investigate variation across European and North American populations. Four single nucleotide polymorphisms (SNPs) were identified and analysed using restriction fragment length polymorphism (RFLP) analysis, together with one insertion/deletion site (Indel) (Table 1). These were used to define composite haplotypes for this gene region, which served as markers of the gene and its associated genome region. PCR amplifications of the GH1 loci were performed in a total volume of $20 \mu$ l containing 1 to $3 \mathrm{ng} \mathrm{ul}^{-1}$ DNA, $75 \mathrm{mM}$ Tris- $\mathrm{HCl}$ (pH 8.8), $20 \mathrm{mM}$ $\left(\mathrm{NH}_{4}\right)_{2} \mathrm{SO}_{4}, 1.5 \mathrm{mM} \mathrm{MgCl}, 250 \mu \mathrm{M}$ of each dNTP, $0.5 \mu \mathrm{M}$ of each primer (sequences obtained from Ryynänen \& Primmer 2004b) and 0.25 units of ABgene Taq DNA polymerase. PCR cycling conditions were performed according to Ryynänen \& Primmer (2004b). Restriction digests were carried out in a $20 \mu l$ reaction volume comprising 2 to $5 \mu \mathrm{l}$ of PCR product and $2 \mathrm{U}$ of restriction enzyme (Table 1). Digests were incubated overnight at the manufacturer's specified temperature and electrophoresis carried out on ethidium bromide stained $3 \%$ agarose gels.

Statistical analysis. Differences in survival rate between families were assessed for significance using a chi-square test. Due to the bimodal growth-related trait distributions observed here, a phenomenon common in most Atlantic salmon populations (Thorpe 1977, Heggenes \& Metcalfe 1991), a principal component analysis (PCA), based on the correlation matrix between the phenotypic traits, was performed within both the PKD survivors and unexposed fish to split the fish into 2 groups according to their developmental status, a lower modal (parr) and an upper modal (smolts) group. Discrimination analysis was carried out to provide an estimate of the distance (Mahanalobis $D^{2}$ ) between the groups and to test for its significance. The PCA made it possible to compare differences in means (Mann-Whitney $U$-test) and distributions (2-sample Kolmogorov-Smirnov test) of fish size and condition between PKD survivors and unexposed fish within both developmental groups.

Potential size-selective mortality was investigated by: (1) testing for differences in the proportion of parr:smolts in the PKD survivors and unexposed fish, and (2) by comparing trait distributions (2-sample Kolmogorov-Smirnov tests) on standardised data. Distributions were standardised to obtain trait means of 0 for the PKD survivors and unexposed group, separately, by subtracting the trait means from the individual data. It was then possible to examine whether the character of the trait distributions had altered.

Single marker allele frequency differences between PKD survivors and unexposed fish were compared by chi-square analysis for dam and sire, separately. The 
Table 1. Salmo salar. Details of Atlantic salmon (a) microsatellite and (b) growth hormone 1 gene (GH1) loci used. GenBank accession numbers are given for microsatellites, while locus name, restriction enzyme/Indel description, and fragment sizes are given for $G H 1$ loci. nd = no data

\begin{tabular}{|c|c|c|}
\hline \multicolumn{3}{|c|}{ (a) Microsatellite markers } \\
\hline $\begin{array}{l}\text { (a) Microsatell } \\
\text { Marker }\end{array}$ & Linkage group & $\begin{array}{c}\text { GenBank } \\
\text { accession \# }\end{array}$ \\
\hline Ssa202 & $1^{\mathrm{a}}$ & U43695 \\
\hline Ssa171 & $2^{\mathrm{a}}$ & U43693 \\
\hline Ssosl311 & $3^{\mathrm{a}}$ & Z48597 \\
\hline Ssa42 & $3^{\mathrm{a}}$ & AF019174 \\
\hline Ssa48 & $4^{\mathrm{a}}$ & AF019176 \\
\hline Ssa11 & $5^{\mathrm{a}}$ & U58894 \\
\hline Ssa14 & $6^{\mathrm{a}}$ & $-d$ \\
\hline Ssa164 & $7^{a}$ & AF019152 \\
\hline SSsp3016 & $8^{\mathrm{a}}$ & AY372820 \\
\hline SSsp2201 & $9^{\mathrm{a}}$ & AY081807 \\
\hline Ssosl444 & $10^{\mathrm{a}}$ & Z49997 \\
\hline CmrSS1.22 & $11^{\mathrm{a}}$ & AF020848 \\
\hline Ssa197 & $12^{\mathrm{a}}$ & U43694 \\
\hline Ssa213 & $13^{\mathrm{a}}$ & AF019163 \\
\hline Ssa9 & $14^{\mathrm{a}}$ & AF019197 \\
\hline SSsp2210 & $15^{\mathrm{a}}$ & AY081808 \\
\hline Ssa420 & $5^{\mathrm{b}}$ & AJ402737 \\
\hline Ssa64 & $6^{\mathrm{b}}$ & AF019183 \\
\hline Ssa417 & $11^{\mathrm{b}}$ & AJ402734 \\
\hline Ssa85 & $18^{\mathrm{b}}$ & U43692 \\
\hline Ssa405 & $28^{\mathrm{b}}$ & AJ402722 \\
\hline$\mu 20.19$ & $23^{\mathrm{b}}$ & nd \\
\hline Ssa16 & $26^{\mathrm{b}}$ & AF019153 \\
\hline Ssa74 & $12^{\mathrm{b}}$ & AF019187 \\
\hline SSsp1605 & $18^{\mathrm{c}}$ & AY081812 \\
\hline SSsp2216 & $7^{c}$ & AY081811 \\
\hline$u F 43$ & Unlinked & U37494 \\
\hline Ssleen82 & Unlinked & U86706 \\
\hline Rsa172 & Unlinked & AF271582 \\
\hline Hae050 & Unlinked & AF271499 \\
\hline Ssa138 & Unlinked & U58902 \\
\hline Ssa65 & Unlinked & AF019184 \\
\hline Hae029 & Unlinked & $\mathrm{AF} 271486$ \\
\hline Hae065 & Unlinked & AF271510 \\
\hline \multicolumn{3}{|l|}{ (b) GH1 loci } \\
\hline Polymorphism & $\begin{array}{l}\text { Restriction enzyme/ } \\
\text { Indel description }\end{array}$ & $\begin{array}{l}\text { Fragment } \\
\text { sizes }\end{array}$ \\
\hline$S N P 2$ & MnlI & $\begin{array}{l}\text { A: } 164,131 \\
\text { B: } 295\end{array}$ \\
\hline SNP3 & $X b a I$ & $\begin{array}{l}\text { A: } 102,550 \\
\text { B: } 652\end{array}$ \\
\hline SNP4 & $T s p 509 \mathrm{I}^{\mathrm{e}}$ & $\begin{array}{l}\text { A: } 392,105,69,46,40 \\
\text { B: } 432,105,69,46\end{array}$ \\
\hline SNP5 & DdeI & $\begin{array}{c}\text { A: } 212,440 \\
\text { B: } 652\end{array}$ \\
\hline Indel1 & TGTGTGTGTGTA & $\begin{array}{l}\text { A: } 217 \\
\text { B: } 205\end{array}$ \\
\hline \multicolumn{3}{|c|}{ 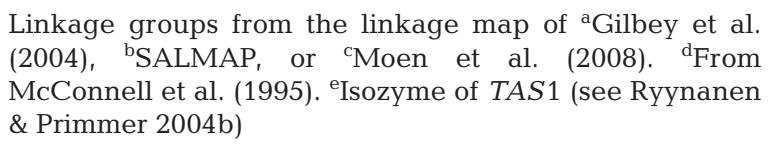 } \\
\hline
\end{tabular}

linkage relationships of the GH1 gene variants resolved were established by comparing observed offspring genotypes in the control group with those predicted for different phase relationships in the parents in each family. As no recombination was detected, the composite parental haplotypes could then be used as markers for the GH1 gene and its associated gene region in the same way as the allelic variants of the microsatellite loci screened. The results of the tests for each marker for each dam and sire can be viewed as independent tests of the same hypothesis, i.e. that the gene region linked to that marker has been differentially selected for among PKD survivors. Thus, the results obtained for each family can be considered collectively for each marker using Fisher's method for combining probabilities (Sokal \& Rohlf 1995), to test for the overall significance of changes in allele frequency observed. These significance levels were then corrected for carrying out multiple tests of marker association with phenotypic variation (i.e. 35 independent overall tests) using a sequential Bonferroni procedure.

The relatedness of the $F_{1}$ parents that were used to produce the informative families was determined by carrying out likelihood analysis using the Kinship program (Goodnight \& Queller 1999). This program was run for 100000 iterations under the null hypothesis that the parental individuals were unrelated, the alternative hypothesis being that the parents were full sibs.

Within the PKD survivors, associations between each growth-related trait and genetic marker were examined using a generalised linear model (GLM). In Atlantic salmon, there is a potential complication in such analyses because recombination in males is severely reduced compared to females (Gilbey et al. 2004, Moen et al. 2004b). This is dealt with in the model used by looking at the male and female effects separately, as well as their interaction. Due to the low numbers of survivors ( $\mathrm{n}=8)$, Family 3 was not included in the analysis. An initial GLM was created to test for the effects of family, development status, and their interaction on each phenotypic trait. The model was then extended to include genetic information. The 2 models were:

Partial model:

$$
Y_{i j k l}=c+f_{i}+d_{j}+\left(f_{i} \times d_{j}\right)+\varepsilon_{i j}
$$

Full model:

$$
\begin{aligned}
Y_{i j k l} & =c+\left(f_{i}+d_{j}+\left(f_{i} \times d_{j}\right)\right) / \\
& \left(M F_{k}+M M_{l}+M F_{k} \times M M_{l}\right)+\varepsilon_{i j k l}
\end{aligned}
$$

where $Y_{i j}$ is the phenotypic parameter of the ith individual with the $j$ th development status; $C$ is a constant; $f_{i}$ is the effect of family; $d_{j}$ is the effect of development status, $M F_{k}$ is the effect of the marker allele inherited from the female parent, $M M_{l}$ is the effect of the marker 
allele inherited from the male parent, and $\varepsilon$ is the random residual associated with each individual.

The significance of the difference between the partial (Eq. 1) and the full (Eq. 2) models was analysed for individual markers and growth-related traits using an $F$-test, and the difference in $\mathrm{R}^{2}$ between the 2 models was taken as the amount of variance explained by the trait-marker association. In cases where there was a significant difference between the models, sex-specific analysis was carried out by creating 2 additional GLMs of the same design, which were then used to investigate the dam and sire components, separately. To address the issue of significance levels where multiple tests are carried out, a sequential method, based on Fisher's approach for testing the overall significance of a set of probabilities, was used. Fisher's method is based on testing the distribution of probabilities observed compared to the distribution expected if the probabilities are purely the result of chance, in this case chance associations. Where a significant departure in the distribution of probabilities across markers was detected, the most extreme probability was removed sequentially and the set of probabilities retested; this was repeated until the overall test was no longer significant. This made it possible to demonstrate whether the extreme values, and how many of them, contributed to obtaining the significant departure of the probability distribution from that expected under the null hypothesis, namely that the distribution was due to random associations. This distributional test was applied to each growth-related trait individually, as the 3 growth-related traits used were not independent of each other.

\section{RESULTS}

The overall survival of the exposed fish was $10 \%(\mathrm{n}=$ 120), but this varied significantly among families $\left(\chi_{3}^{2}=\right.$ 35.96, $\mathrm{p}<0.0001$ ), with highest survival in Family 4
(17.67\%), followed by Family 1 (12\%), Family 2 (7\%), and the lowest in Family $3(2.67 \%)$. PCA of the data revealed a single discriminatory factor that explained $97.36 \%$ and $98.72 \%$ of phenotype variation of the PKD survivors and unexposed fish, respectively. Discriminant analysis showed significant differences between the PCA-split groups in both PKD survivors (Mahanalobis $D^{2}=35.14, F=620.2, \mathrm{p}<0.0001$ ) and unexposed fish (Mahanalobis $D^{2}=18.99, F=191.5, \mathrm{p}<0.0001$ ).

On average, both parr and smolts of the PKD survivors were significantly smaller and had a lower condition factor compared to the unexposed group (Table 2). Mean parr length of the PKD survivors was $8 \%$ less, mean weight was $30 \%$ lower, and mean condition factor $3 \%$ lower; mean smolt length of the PKD survivors was $16 \%$ less, mean weight was $47 \%$ lower, and mean condition factor $7 \%$ lower. The trait distributions for both parr and smolts were 'shifted' towards smaller individuals in the PKD survivors compared to unexposed fish in all families, resulting in significant differences in the distributions (Table 2). Though parr and smolts of the PKD survivors were smaller and had lower condition factors than the unexposed group, the proportion of parr to smolts did not differ between the two groups $\left(\chi_{3}^{2}=0.013, p=0.91\right)$, with $21.67 \%$ (26 of 120) and $22.89 \%$ (46 of 201) of fish classified as smolts in the PKD survivors and unexposed group, respectively. Furthermore, the shapes of the standardised trait distributions were not significantly different in either parr (weight: $p=0.36$; length: $p=0.87 ; C F: p=0.45$ ) or smolts (weight: $p=0.053$; length: $p=0.41$; $\mathrm{CF}: \mathrm{p}=0.09$ ).

Prior to correction for multiple tests, significant allele frequency differences between the PKD survivors and the unexposed group were found for 4 microsatellite markers (Ssa14, Hae050, Ssa85, and Ssleen82) and the GH1 locus (Table 3). These were all observed in single parents and were significant only in the dams and sires of Family 1 and Family 4. After combining the probabilities across families, sequential Bonferroni correction showed that significant allele frequency differ-

Table 2. Salmo salar. Differences in means and distributions of weight, length, and condition factor (CF) of parr and smolts between proliferative kidney disease (PKD) survivors and unexposed fish. Significance of means examined using Mann-Whitney $U$-tests; trait distributions analysed with Kolmogorov-Smirnov 2-sample tests (K-S test). $\mathrm{n}=$ no. of individuals. Significance levels: ${ }^{*} \mathrm{p}<0.05,{ }^{* *} \mathrm{p}<0.01,{ }^{* * *} \mathrm{p} \leq 0.001$

\begin{tabular}{|c|c|c|c|c|c|c|c|c|c|}
\hline \multirow[t]{2}{*}{ Trait } & \multirow{2}{*}{ Group } & \multicolumn{3}{|c|}{$\ldots$ Unexposed fish } & \multicolumn{3}{|c|}{ PKD survivors } & \multirow{2}{*}{$\begin{array}{c}U \text {-test } \\
\mathrm{p}\end{array}$} & \multirow{2}{*}{$\begin{array}{c}\text { K-S test } \\
\mathrm{p}\end{array}$} \\
\hline & & $\mathrm{n}$ & Mean & CI $(95 \%)$ & $\mathrm{n}$ & Mean & CI $(95 \%)$ & & \\
\hline \multirow[t]{2}{*}{ Weight } & Parr & 155 & 15.36 & $14.65-16.08$ & 94 & 11.09 & $10.38-11.80$ & *** & *** \\
\hline & Smolts & 46 & 50.81 & $47.59-54.03$ & 26 & 26.95 & $25.08-28.82$ & $* * *$ & $* * *$ \\
\hline \multirow[t]{2}{*}{ Length } & Parr & 155 & 97.14 & $95.49-98.78$ & 94 & 91.92 & $89.94-93.91$ & $* * *$ & $* *$ \\
\hline & Smolts & 46 & 156.78 & $153.86-159.71$ & 26 & 131.27 & $126.35-136.19$ & $* * *$ & $* * *$ \\
\hline \multirow[t]{2}{*}{$\mathrm{CF}$} & Parr & 155 & 1.57 & $1.53-1.61$ & 94 & 1.39 & $1.36-1.43$ & $* * *$ & $* * *$ \\
\hline & Smolts & 46 & 1.30 & $1.27-1.34$ & 26 & 1.21 & $1.11-1.32$ & $* * *$ & $* * *$ \\
\hline
\end{tabular}


ences remained for the markers Ssa14, Ssa85, Ssleen82, and GH1 (Table 3).

The kinship analysis revealed that the parental fish that were used to create Family 1 were full sibs ( $p=$ 0.001), whilest the parental fish used to create the other 3 families were not. Those individuals were, due to the single mating design, less inbred than half sibs. Interestingly, Family 1 showed the most and strongest associations.

For all 3 growth-related traits, variation was significantly associated with a number of microsatellite markers prior to correction for multiple tests (Table 4). These explained between 1.9 and $7.1 \%$ of the variance in weight, between 2.8 and $7.4 \%$ of the variance in length, and between 10.6 and $21.9 \%$ of the variance in condition factor. The significant component of these associations was variously associated with variation at either the dam or sire, with a significant dam component in 4 out of 5 associations with weight, explaining between 4.0 and $7.1 \%$ of its variance, in 2 out of 5 cases in relation to length, where it explained between 0.4 and $6.4 \%$, and in 3 out of the 4 associations with $\mathrm{CF}$, with between 5.0 and $7.6 \%$ of the variance explained (Table 4). Allelic variation in the sire explained between 2.0 and $5.0 \%$ of the variance in weight, $7.4 \%$ of the variance in length, and $12.9 \%$ of the variation in $\mathrm{CF}$.

The distributions of probabilities for the markers showed a significant departure from expected in relation to weight $(p=0.003)$ and length $(p=0.007)$, and was nearly significant with respect to condition factor $(p=0.071)$. Sequential application of the Fisher's test indicated that the 3 most significantly associated markers in relation to weight $(\mu 20.19$, SP3016, Ssa14) contributed to the significant departure of the distribution of probabilities for this trait. Excluding these, the pvalue for the Fisher's test was 0.099. This was also the case with regards to length, after the first 2 individually significant marker values (Sp3016, Ssa48) were excluded ( $p=0.127$ ). In the case of condition factor, the exclusion of the one most significant value (Ssa16) made the Fisher's test highly non-significant ( $\mathrm{p}=$ 0.284). Similar results were found in the sex-specific analysis, though these were all related to the dambased analysis. The p-values associated with the markers $\mu 20.19$ and Ssa11 remained significant in relation to weight after correction for multiple tests, while SP3016 and $S_{s a 48}$ remained significantly associated with length and $\mathrm{CF}$, respectively. The omission of those $\mathrm{p}$ values turned the Fisher's test non-significant (weight: $p=0.164$; length: $p=0.184$; $C F: p=0.062$ ). In the sire, none of the $\mathrm{p}$-values remained significant after correction. The only marker appearing, prior to correction for multiple tests, to give a significant association in relation to all 3 traits is SP3016 and 3 markers ( $\mu 20.19$, $S s a 48$, and $S_{s a} 9$ ) do so in relation to 2 of the traits.

\section{DISCUSSION}

The present study shows significant phenotypic and genotypic differences in the PKD survivors compared to unexposed fish from the same families. PKD survivors were, on average, smaller and condition factor was lower in both parr and smolts. Mortality did not appear to be size-selective, as the parr:smolt ratio and the character/shape of the trait distributions were similar in both groups, suggesting rather that there had been a difference in growth performance between the 2 groups. Additionally, differences were observed in the allele frequencies between the groups with respect to 5 markers, 4 microsatellite and 1 GH1 markers. Furthermore, there was evidence supporting associations of at least 6 markers with growth-related traits.

Table 3. Salmo salar. Significant $\chi^{2}$ tests for allele frequency differences between proliferative kidney disease (PKD) survivors and unexposed fish, assessed for dam and sire separately within each family. p-values in italics are significant. Fisher's test for combining probabilities was used to test for significance across all families. $p$-values in bold are significant $(p<0.0015)$ after correction for multiple tests (sequential Bonferonni) of the combined p-values. nd $=$ no data; na $=$ dam/sire was homozygous for that particular marker

\begin{tabular}{|c|c|c|c|c|c|c|}
\hline Marker & Parent & Family 1 & Family 2 & Family 3 & Family 4 & Across all families \\
\hline Ssa14 & $\begin{array}{l}\text { Dam } \\
\text { Sire }\end{array}$ & $\begin{array}{c}0.645 \\
<0.0001\end{array}$ & $\begin{array}{c}0.114 \\
\text { na }\end{array}$ & $\begin{array}{l}0.198 \\
0.832\end{array}$ & $\begin{array}{c}0.033 \\
\text { na }\end{array}$ & $<0.0001$ \\
\hline Hae050 & $\begin{array}{l}\text { Dam } \\
\text { Sire }\end{array}$ & $\begin{array}{l}0.313 \\
0.004\end{array}$ & $\begin{array}{l}0.131 \\
0.885\end{array}$ & $\begin{array}{l}0.713 \\
0.732\end{array}$ & $\begin{array}{l}1.000 \\
0.330\end{array}$ & 0.1712 \\
\hline Ssa85 & $\begin{array}{l}\text { Dam } \\
\text { Sire }\end{array}$ & $\begin{array}{c}0.0001 \\
\text { na }\end{array}$ & $\begin{array}{l}\text { nd } \\
\text { nd }\end{array}$ & $\begin{array}{l}0.652 \\
0.652\end{array}$ & $\begin{array}{c}0.110 \\
\text { na }\end{array}$ & 0.0019 \\
\hline Ssleen82 & $\begin{array}{l}\text { Dam } \\
\text { Sire }\end{array}$ & $\begin{array}{l}0.630 \\
0.924\end{array}$ & $\begin{array}{l}0.106 \\
0.073\end{array}$ & $\begin{array}{c}\text { na } \\
0.317\end{array}$ & $\begin{array}{l}0.133 \\
0.002\end{array}$ & 0.0088 \\
\hline GH1 & $\begin{array}{l}\text { Dam } \\
\text { Sire }\end{array}$ & $\begin{array}{l}0.004 \\
0.309\end{array}$ & $\begin{array}{l}0.139 \\
0.308\end{array}$ & $\begin{array}{l}0.572 \\
0.459\end{array}$ & $\begin{array}{l}0.344 \\
0.216\end{array}$ & 0.0351 \\
\hline
\end{tabular}


Table 4. Salmo salar. Generalized linear model (GLM) of associations between markers and weight, length, and condition factor of the proliferative kidney disease (PKD) survivors. Linkage group (LG) is divided into markers derived from the linkage maps of Gilbey et al. (2004) and SALMAP. p-values are associated with differences between the proportion of variation $\left(\mathrm{R}^{2}\right)$ explained by the partial (Eq. 1) and full (Eq. 2) models, which encompassed analysis of both dam (D) and sire (S) components combined and analysed separately. See text for GLM details. p-values in bold are significant after correction for multiple tests. nd = no data

\begin{tabular}{|c|c|c|c|c|c|c|c|c|c|c|c|}
\hline Marker & LG & $\mathrm{R}^{2}$ partial & $\mathrm{R}^{2}(\mathrm{D}+\mathrm{S})$ & Differenc & ce $p$ & $\mathrm{R}^{2}(\mathrm{D})$ & Difference & e p & $\mathrm{R}^{2}(\mathrm{~S})$ & Difference & $p$ \\
\hline \multicolumn{12}{|l|}{ Weight } \\
\hline$\mu 20.19$ & $23^{b}$ & 67.9 & 71.9 & 4.0 & 0.002 & 71.9 & 4.0 & 0.002 & nd & nd & nd \\
\hline SP3016 & $8^{\mathrm{a}}$ & 67.9 & 75.0 & 7.1 & 0.016 & 75.0 & 7.1 & 0.005 & 71.1 & 3.2 & 0.406 \\
\hline Ssa14 & $6^{\mathrm{a}}$ & 67.9 & 72.6 & 4.7 & 0.033 & 73.6 & 5.7 & 0.004 & 68.5 & 0.6 & 0.878 \\
\hline Ssa9 & $14^{\mathrm{a}}$ & 67.9 & 72.9 & 5.0 & 0.04 & 71.4 & 3.5 & 0.062 & 72.9 & 5.0 & 0.040 \\
\hline Ssa42 & $3^{\mathrm{a}}$ & 78.4 & 80.3 & 1.9 & 0.05 & 78.0 & -0.4 & 0.511 & 80.4 & 2.0 & 0.022 \\
\hline Ssa11 & $5 a$ & 67.9 & 73.1 & 5.2 & 0.05 & 73.8 & 5.9 & 0.002 & 68.8 & 0.9 & 0.526 \\
\hline \multicolumn{12}{|l|}{ Length } \\
\hline SP3016 & $8^{a}$ & 77.1 & 83.3 & 6.2 & 0.002 & 83.5 & $6.4<$ & $<0.001$ & 79.1 & 2.0 & 0.434 \\
\hline Ssa48 & $4^{\mathrm{a}}$ & 77.1 & 80.5 & 3.4 & 0.006 & 77.5 & 0.4 & 0.026 & 75.1 & -2.0 & 0.777 \\
\hline$\mu 20.19$ & $23^{b}$ & 77.1 & 79.9 & 2.8 & 0.012 & 79.9 & 2.8 & 0.12 & nd & nd & nd \\
\hline Ssa9 & $14^{\mathrm{a}}$ & 77.1 & 84.5 & 7.4 & 0.035 & 83.3 & 6.2 & 0.109 & 84.5 & 7.4 & 0.035 \\
\hline \multicolumn{12}{|c|}{ Condition factor } \\
\hline Ssa16 & $26^{\mathrm{b}}$ & 25.4 & 47.3 & $21.9<$ & $<0.001$ & 31.7 & 6.3 & 0.008 & 38.3 & 12.9 & 0.003 \\
\hline Ssa48 & $4^{\mathrm{a}}$ & 25.4 & 41.1 & 15.7 & 0.002 & 33.0 & 7.6 & 0.003 & 21.9 & -3.5 & 0.689 \\
\hline SP3016 & $8^{a}$ & 25.4 & 36.0 & 10.6 & 0.009 & 30.4 & 5.0 & 0.034 & 27.6 & 2.2 & 0.083 \\
\hline Ssa74 & $12^{\mathrm{b}}$ & 25.4 & 37.3 & 11.9 & 0.036 & 29.0 & 3.6 & 0.459 & 32 & 6.6 & 0.072 \\
\hline \multicolumn{12}{|c|}{$\begin{array}{l}{ }^{\mathrm{a}} \text { Gilbey et al. (2004) } \\
{ }^{\mathrm{b}} \text { SALMAP }\end{array}$} \\
\hline
\end{tabular}

The observed phenotypic change indicated a 'shift' in the means and distributions of the size of fish towards smaller individuals in the PKD survivors compared to the unexposed group of fish. These 'shifts' could be explained either by environmental influences associated with the different conditions under which the fish were retained, or by a cost associated with mounting an immune response, with resources reallocated to this response rather than to growth. Although fish were kept at equal densities and were fed ad lib, both groups of fish were kept in different environments and were treated differently with respect to the antibiotic, which could have affected growth performance through loss of appetite (Villareal et al. 1988, Björnsson et al. 1989, Solbakken et al. 1994). However, despite the environmental differences between the hatcheries, it may be assumed that the influences on growth were similar for both sites, i.e. the environmental conditions and hatchery practices were not such as to favour growth at a particular site. As such, growth differences between the 2 groups due to environmental and treatment differences would have been expected to be less marked than was observed. In other words, it is unlikely these factors could have led to the extreme growth differences and pattern observed.

In both environments, growth may have been expected to be similar or perhaps even faster in smolts than in parr, as the former would have been more com- petitive and would therefore have acquired more food (Thorpe 1977, Metcalfe et al. 1989). However, this is contrary to what was observed, with smolts growing more slowly than parr in the PKD survivors, which suggests that the reduced growth was due to the PKD infection. Studies on pigs (van Heugten et al. 1996), Japanese quail Coturnix coturnix japonica (Fair et al. 1999), and salmonids (Ellis et al. 1985) have also reported weight loss and reduced growth associated with mounting an immune response. Ellis et al. (1985) found that the first signs of infection with PKD coincided with a significant reduction in growth rate in brown trout Salmo trutta and Atlantic salmon parr. As such, it is likely that the PKD infection resulted in the observed reduction in growth of both parr and smolts. Therefore, the reduced growth observed is consistent with the view that a cost is associated with mounting an immune response. Indeed, other studies support the view that a trade-off exists between allocating resources and energy towards pathogen resistance or to other fitness-related traits such as growth and maturation/reproduction (Sheldon \& Verhulst 1996, Bakke \& Harris 1998, Lochmiller \& Deerenberg 2000, Colditz 2002). The larger mean differences in fish size and condition observed in smolts compared to parr could be explained by the added energetic/metabolic cost associated with the parr-smolt transformation (Mesa et al. 1999, Glover et al. 2006), which these fish are likely to have been undergoing at the time of the 
PKD outbreak. Consequently, resources might have been allocated towards completion of the various changes undertaken during smoltification, resulting in there being less available for growth in smolts than in parr.

Where testable, allele frequency differences between PKD survivors and unexposed fish were always found to be significant in relation to allelic variation associated with one parent and were not always significant within and across families. Furthermore, the direction of the change in allele frequencies between the groups was variable among parents, with no consistent association of specific allele frequency changes with mortality across families. As such, this makes it impossible to say much about the nature and biological significance of the frequency differences observed, other than that the genetic architecture of the resistance response is probably complex. Also, due to the outbred nature of the families, it would be expected that most parents would not be informative for most markers and that the associations, therefore, were family-specific. Furthermore, it points to polygenic control of disease resistance, as found in other studies (Gilbey et al. 2006, Barroso et al. 2008), with the likelihood that loci with useful variation in mounting an immune response vary among families.

Nine markers showed significant trait associations prior to correcting for multiple tests, despite the low numbers of PKD survivors and the 1 marker per linkage group approach used. Of these, 4 ( $\mu 20.19$, SP3016, Ssa14, and Ssa48) continued to show statistically significant associations when the adjustment for multiple tests was made, representing 4 different linkage groups. Interestingly, Gilbey (2003) reported the markers Ssa14, Ssa48, and $\mu 20.19$ to be significantly associated with QTL affecting fish size during development from parr to smolt in backcrosses between Scottish and Canadian Atlantic salmon. Additionally, Boulding et al. (2008) found SNP markers on linkage groups AS9, AS18, and AS22 (derived from ASalBASE; http://www. asalbase.org) to be associated with weight and condition factor and markers on AS10 and AS12 to be linked to morphometric variables in trans-Atlantic crosses of Atlantic salmon. Those linkage groups contain the microsatellites markers SP3016, Ssa85, Ssa16, Ssa48, and $S$ sa 74 , respectively, which were found to be associated with growth-related traits in the present study. Similarly, Ssa42 was found to be linked to QTL involved in resistance to Gyrodactylus salaris (Gilbey et al. 2006), and population differentiation between Scottish and Baltic populations was markedly higher at that marker in comparison with 15 other microsatellite markers (C. Thompson et al. unpubl. data), of which 5 were identified as being significantly associated with resistance to G. salaris (Gilbey et al. 2006).
A nucleotide-nucleotide basic local alignment search tool (BLAST) search was carried out on the markers that showed either significant allele frequency differences between the 2 groups or markertrait associations, using 'in silico data mining' of the GenBank database, based on the procedure outlined by Cnaani et al. (2002). Though the chance of finding a QTL located next to a marker is very small, due to the approach taken, this was done to see if any of these microsatellites could be immediately linked to gene regions that could, by the nature of their function, be responsible for the observed associations. The flanking regions of only one marker, $S$ sa42, produced an interesting result. It showed a homology (94\%; 48/51 bp; e value: $3 \times 10^{-11}$ ) with sequences of the immune-related genes Synaptic Ras-GTPase-activating protein 1, PHD finger protein 1, and Ral guanine nucleotide dissociation stimulator-like 2 (GenBank accession \#DQ246664) in rainbow trout. These genes belong to the extended major histocompatibility complex (MHC) class II region, described by Palti et al. (2007). Thus, this marker appears to be closely associated with a part of the MHC complex involved in pathogen resistance and may be a key element in the overall genomic architecture of resistance to a number of disease vectors, despite it no longer being significantly associated with weight.

The amount of variation explained by the associations of markers with growth-related traits varied between 1.9 and $21.9 \%$, though this variation was lower, i.e. from 0.4 to $7.6 \%$, when the dam and sire components were analysed separately. The variation explained by them did follow the expected exponential distribution (Orr 1998, Barton \& Keightley 2002). However, due to the approach taken, where each microsatellite potentially marked a complete chromosome, it can be assumed that the observed trait variance potentially represented the cumulative effect of an unknown but potentially large number of QTL on that particular linkage group. Each growth-related trait measured was associated with variation at a number of markers on different linkage groups. A total of 8 linkage groups were identified as being associated with the traits, supporting a model of polygenic control of growth, as reported in other studies (Reid et al. 2005, Boulding et al. 2008).

Interestingly, in the sex-specific analysis, the significant associations, after correction for multiple tests, were observed in the dam, where recombination is more frequent that in males (Gilbey et al. 2004, Moen et al. 2004b). As such, despite the single marker-single linkage group approach taken here, whereby each marker represented a whole linkage group/chromosome, the distance between the marker and putative QTL may be expected to be smaller than if the associations were observed in the males. 
One marker, Ssa14, showed both significant allele frequency differences between the unexposed and exposed groups and was significantly associated with weight within the PKD survivors. This could reflect real or apparent (due to linkage of the QTL involved in the resistance and growth responses) pleiotropy. The number of unexposed fish ( $\mathrm{n}=305)$ was large enough to accurately estimate the original distribution of alleles across the 4 families, even though data could not be collected from the PKD mortalities. The results for this marker may also indicate that, although different QTL might be involved, there may be an association between QTL influencing growth and resistance.

The analysis of GH1 revealed allele frequency differences between the PKD survivors and the unexposed group. This suggests that the GH1 gene itself could be linked to the observed pathogen resistance. Kuhnlein et al. (1997) reported consistent differences in allele frequencies of the $G H$ gene in resistanceselected strains of white leghorn chickens, further evidence that allelic variation at this gene could affect resistance. However, it is more likely that the allele frequency differences observed in GH1 were the result of linkage with other QTL that reside on the same linkage group. More detailed, fine-scale mapping of this linkage group could help to determine the extent to which the GH1 locus itself is directly involved.

The observation that the allele frequency differences and marker-trait associations were not universal across families could reflect the fact that the genetic architecture of resistance is complex and variable among individuals, and is due to the outbred nature of the crosses. However, it could also reflect the relatedness of the $F_{2}$ crosses used. The majority of the allele frequency differences and highest significance levels were found in Family 1, the only family created by full sib parents. Families created by full sib parents, if containing relevant variation, have been shown to potentially be more informative with regards the trait of interest than less inbred families (Xie et al. 1998) and provide a more powerful mating design for association detection. This reinforces the probable biological significance of the observed associations.

Further large- and fine-scale mapping studies, focusing on the linkage groups identified, are needed to ascertain whether the markers identified here are closely linked and universal or just family-specific. More extensive studies of wild populations and aquaculture strains would also be helpful for establishing if the associations are widespread and consistent, focusing on the analysis of families from full-sib crosses. This would help with examining the potential usefulness of markers on these linkage groups in marker-assisted selective (MAS) breeding for pathogen resistance. The single marker-single linkage group approach used here points to some linkage groups that are potentially a part of the genomic architecture of resistance to PKD in Atlantic salmon. The reported findings should help guide future work aimed at finding the gene regions and QTL involved in the resistance response to PKD. Given the time taken to carry out informative familybased QTL-type studies, our findings will help to effectively focus future work.

Acknowledgements. The authors thank M. Miles and staff at the Marine Scotland Science Freshwater Laboratory (MMS FL) Rearing Unit at Almondbank, Perthshire, Scotland, and P. MacLachlan and staff at the Marine Scotland Science Fish Cultivation Unit at Aultbea, Ross-shire, Scotland, for their help with rearing and sampling of the fish. Furthermore, we thank A. Warwick from the FRS Fish Health Inspectorate for carrying out the pathological analyses.

\section{LITERATURE CITED}

Alexander M (1981) Why microbial predators and parasites do not eliminate their prey and hosts. Rev Microbiol 35: 113-133

Bakke TA, Harris PD (1998) Diseases and parasites in wild Atlantic salmon (Salmo salar). Can J Fish Aquat Sci 55: $247-266$

> Bakke TA, Harris PD, Hansen H, Cable J, Hansen P (2004) Susceptibility of Baltic and East Atlantic salmon Salmo salar stocks to Gyrodactylus salaris (Monogenea). Dis Aquat Org 58:171-177

> Barroso RM, Wheeler PA, LaPatra SE, Drew RE, Thorgaard GH (2008) QTL for IHNV resistance and growth identified in a rainbow (Oncorhynchus mykiss) $\times$ Yellowstone cutthroat (Oncorhynchus clarki bouvieri) trout cross. Aquaculture 277:156-163

> Barton NH, Keightley PD (2002) Understanding quantitative genetic variation. Nat Rev Genet 3:11-21

> Björnsson BTh (1997) The biology of salmon growth hormone: from daylight to dominance. Fish Physiol Biochem 17:9-24

Björnsson BTh, Thorarensen $\mathrm{H}$, Hirano $\mathrm{T}$, Ogasawara $\mathrm{T}$, Kristinsson JB (1989) Photoperiod and temperature affect plasma growth hormone levels, growth, condition factor and hypoosmoregulatory ability of juvenile Atlantic salmon (Salmo salar) during parr-smolt transformation. Aquaculture 82:77-91

Boulding EG, Culling M, Glebe B, Berg PR, Lien S, Moen T (2008) Conservation genomics of Atlantic salmon: SNPs associated with QTLs for adaptive traits in parr from four trans-Atlantic backcrosses. Heredity 101:381-391

Brown JA, Thonney JP, Holwell D, Wilson WR (1991) A comparison of susceptibility of Salvelinus alpinus and Salmo salar ouananiche to proliferative kidney disease. Aquaculture 96:1-6

Butterfield GM (2008) Genetic variation for disease resistance in rainbow trout (Oncorhynchus mykiss). $\mathrm{PhD}$ dissertation, University of Stirling

Cnaani A, Ron M, Hulata G, Seroussi E (2002) Fishing in silico: searching for tilapia genes using sequences of microsatellite DNA markers. Anim Genet 33:474-476

Colditz IG (2002) Effects of the immune system on metabolism: implications for production and disease resistance in livestock. Livest Prod Sci 75:257-268

Coltman DW, Pilkington J, Kruuk LEB, Wilson K, Pemberton JM (2001) Positive genetic correlation between parasite 
resistance and body size in a free-living ungulate population. Evolution 55:2116-2125

Ellis AE, McVicar AH, Munro ALS (1985) Proliferative kidney disease in brown trout, Salmo trutta L., and Atlantic salmon, Salmo salar L., parr: histopathological and epidemiological observations. J Fish Dis 8:197-208

$>$ Ewald PW (1983) Host-parasite relations, vectors, and the evolution of disease severity. Annu Rev Ecol Syst 14: 465-485

Fair JM, Hansen ES, Ricklefs RE (1999) Growth, developmental stability and immune response in juvenile Japanese quails (Coturnix coturnix japonica). Proc Biol Sci 266: 1735-1742

Feist SW, Bucke D (1993) Proliferative kidney disease in wild salmonids. Fish Res 17:51-58

Gilbey JA (2003) Genetic mapping of quantitative trait loci influencing growth, development and morphology in Atlantic salmon (Salmo salar L.). PhD dissertation, University of Aberdeen

Gilbey J, Verspoor E, McLay A, Houlihan D (2004) A microsatellite map for Atlantic salmon (Salmo salar). Anim Genet 35:98-105

Gilbey J, McLay A, Houlihan D, Verspoor E (2005) Individuallevel analysis of pre- and post-first-feed growth and development in Atlantic salmon. J Fish Biol 67:1359-1369

Gilbey J, Verspoor E, Mo TA, Sterud E and others (2006) Identification of genetic markers associated with Gyrodactylus salaris resistance in Atlantic salmon (Salmo salar L.). Dis Aquat Org 71:119-129

> Gjedrem T (2000) Genetic improvement of cold-water species. Aquacult Res 31:25-33

> Gjedrem T, Salte R, Gjoen HM (1991) Genetic variation in susceptibility of Atlantic salmon to furunculosis. Aquaculture 97:1-6

Glover KA, Skår C, Christie KE, Glette J, Rudra H, Skaala Ø (2006) Size-dependent susceptibility to infectious salmon anemia virus (ISAV) in Atlantic salmon (Salmo salar L.) of farm, hybrid and wild parentage. Aquaculture 254:82-91

Goodnight KF, Queller DC (1999) Computer software for performing likelihood tests of pedigree relationship using genetic markers. Mol Ecol 8:1231-1234

> Hedrick RP, MacConnell E, de Kinkelin P (1993) Proliferative kidney disease of salmonid fish. Annu Rev Fish Dis 3: 277-290

> Heggenes J, Metcalfe NB (1991) Bimodal size distributions in wild juvenile Atlantic salmon populations and their relationship with age at smolt migration. J Fish Biol 39:905-907

Holland JW, Gould CRW, Jones CS, Noble LR, Secombes CJ (2003) The expression of immune-regulatory genes in rainbow trout, Oncorhynchus mykiss, during a natural outbreak of proliferative kidney disease (PKD). Parasitology 126:S95-S102

Houston RD, Haley CS, Hamilton A, Guy DR and others (2008) Major quantitative trait loci affect resistance to infectious pancreatic necrosis in Atlantic salmon (Salmo salar). Genetics 178:1109-1115

Knox D, Lehnmann K, Reddin DG, Verspoor E (2002) Genotyping of archival Atlantic salmon scales from northern Quebec and west Greenland using novel PCR primers for degraded mtDNA. J Fish Biol 60:266-270

Kuhnlein U, Ni L, Weigend S, Gavora JS, Fairfull W, Zadworny D (1997) DNA polymorphisms in the chicken growth hormone gene: response to selection for disease resistance and association with egg production. Anim Genet 28:116-123

Lande R, Thompson R (1990) Efficiency of marker-assisted selection in the improvement of quantitative traits. Genetics 124:743-756

le Gouvello R, Pobel T, Richards RH, Gould C (1999) Field efficacy of a 10-day treatment of fumagillin against proliferative kidney disease in rainbow trout Oncorhynchus mykiss. Aquaculture 171:27-40

> Lochmiller RL, Deerenberg C (2000) Trade-offs in evolutionary immunology: Just what is the cost of immunity? Oikos 88:87-98

McConnell SK, Oreilly P, Hamilton L, Wright JN, Bentzen P (1995) Polymorphic microsatellite loci from Atlantic salmon (Salmo salar) - genetic differentiation of North American and European populations. Can J Fish Aquat Sci 52:1863-1872

Mesa MG, Maule AG, Poe TP, Schreck CB (1999) Influence of bacterial kidney disease on smoltification in salmonids: Is it a case of double jeopardy? Aquaculture 174:25-41

> Metcalfe NB, Huntingford FA, Graham WD, Thorpe JE (1989) Early social status and development of life-history strategies in Atlantic salmon. Proc R Soc Lond B Biol Sci 236:7-19

> Moen T, Fjalestad KT, Munck H, Gomez-Raya L (2004a) A multistage testing strategy for detection of quantitative trait loci affecting disease resistance in Atlantic salmon. Genetics 167:851-858

> Moen T, Hoyheim B, Munck H, Gomez-Raya L (2004b) A linkage map of Atlantic salmon (Salmo salar) reveals an uncommonly large difference in recombination rate between the sexes. Anim Genet 35:81-92

> Moen T, Hayes B, Baranski M, Berg PR and others (2008) A linkage map of the Atlantic salmon (Salmo salar) based on EST-derived SNP markers. BMC Genomics 9:223

Mustafa A, MacKinnon BM (1999) Genetic variation in susceptibility of Atlantic salmon to the sea louse Caligus elongatus Nordmann, 1832. Can J Zool 77:1332-1335

Orr HA (1998) The population genetics of adaptation: the distribution of factors fixed during adaptive evolution. Evolution 52:935-949

Palti Y, Rodriguez MF, Gahr SA, Hansen JD (2007) Evolutionary history of the ABCB2 genomic region in teleosts. Dev Comp Immunol 31:483-498

Price DJ (1985) Genetics of susceptibility and resistance to disease in fishes. J Fish Biol 26:509-519

Reid DP, Szanto A, Glebe B, Danzmann RG, Ferguson MM (2005) QTL for body weight and condition factor in Atlantic salmon (Salmo salar): comparative analysis with rainbow trout (Oncorhynchus mykiss) and Arctic charr (Salvelinus alpinus). Heredity 94:166-172

> Robison BD, Wheeler PA, Sundin K, Sikka P, Thorgaard GH (2001) Composite interval mapping reveals a major locus influencing embryonic development rate in rainbow trout (Oncorhynchus mykiss). J Hered 92:16-22

> Ryynänen HJ, Primmer CR (2004a) Distribution of genetic variation in growth hormone 1 gene in Atlantic salmon (Salmo salar) populations from Europe and North America. Mol Ecol 13:3857-3869

Ryynänen HJ, Primmer CR (2004b) Primers for sequence characterization and polymorphism detection in the Atlantic salmon (Salmo salar) growth hormone 1 (GH1) gene. Mol Ecol Notes 4:664-667

Seagrave CP, Bucke D, Hudson EB, McGregor D (1981) A survey of the prevalence and distribution of proliferative kidney disease (PKD) in England and Wales. J Fish Dis 4: 437-439

> Sheldon BC, Verhulst S (1996) Ecological immunity: costly parasite defences and trade-offs in evolutionary ecology. Trends Ecol Evol 11:317-321

Sokal RR, Rohlf FJ (1995) Biometry: the principles and prac- 
tice of statistics in biological research. W.H. Freeman and Company, New York, NY

Solbakken VA, Hansen T, Stefansson SO (1994) Effects of photoperiod and temperature on growth and parr-smolt transformation in Atlantic salmon (Salmo salar L.) and subsequent performance in seawater. Aquaculture 121:13-27

Thorpe JE (1977) Bimodal distribution of length of Atlantic salmon (Salmo salar L.) under artificial rearing conditions. J Fish Biol 11:175-184

van Heugten E, Coffey MT, Spears JW (1996) Effects of

Editorial responsibility: Catherine Collins, Aberdeen, UK immune challenge, dietary energy density and source of energy on performance and immunity in weanling pigs. J Anim Sci 74:2431-2440

Villarreal CA, Thorpe JE, Miles MS (1988) Influence of photoperiod on growth changes in juvenile Atlantic salmon, Salmo salar L. J Fish Biol 33:15-30

Wootton RJ (1990) Ecology of teleosts fishes. Chapman \& Hall, London

Xie C, Gessler DDG, Xu S (1998) Sib mating designs for mapping quantitative trait loci. Genetica 104:9-19

Submitted: November 20, 2008; Accepted: December 12, 2009 Proofs received from author(s): February 17, 2010 